\title{
MIGRATION MANAGEMENT IN MODERN RUSSIA: ACHIEVEMENTS AND MISCOUNTS ${ }^{1}$
}

\author{
Aleksey I. Bardakov \\ Volgograd Institute of Management - Branch of Russian Presidential Academy of National Economy and Public \\ Administration, Volgograd, Russian Federation
}

\begin{abstract}
Introduction. The paper discloses the main problems of migration in the context of the functioning of the imperious-administrative system in Russia that changes the traditional research vector. This approach allows us considering the organizational aspects of the settlement of migrants rather then the subject of migration. Such focus has a clear correlation with the Russian authorities as the object of research.

Methods. Using the methods of induction and deduction makes understand the private nature of migration in the system of social interrelations and reveal the cause-and-effect relationship of migration processes with the structures of power. The research has been carried out from the general to the specific, i. e. the drawbacks in Russian power structures are dealt with as the general, and then they are projected on the actions of authorities towards migrants. This technique lets avoid mission drift and get the true knowledge on a particular issue.

Analysis. The analysis of power drawbacks in migration management in modern Russia is based on a critical analysis of social migration practices and theoretical research in this area of knowledge. The focus has been made on the limitedness of institutional capacity of public administration in dealing with migration problems. We also indicate the reasons for local communities to participate in migration policy implementation, to disclose the multiple vectors of social and cultural factors influencing the organization of migrants' life, and call in question the necessity of labour migration in Russia.

Results. We've identified seven drawbacks in migration management associated with poor management, the lack of forms of direct democracy, the employers' negative attitude to migrants, and the weakness of civil society. Addressing the identified drawbacks should be based on the improvement of management system by expanding the forms of direct democracy and creating the sustainable mechanism of the people's will expression regarding local issues.
\end{abstract}

Key words: migration, public administration, local government, local community, integration.

Citation. Bardakov A.I. Migration Management in Modern Russia: Achievements and Miscounts. Vestnik Volgogradskogo gosudarstvennogo universiteta. Seriya 4, Istoriya. Regionovedenie. Mezhdunarodnye otnosheniya [Science Journal of Volgograd State University. History. Area Studies. International Relations], 2018, vol. 23, no. 4, pp. 176-185. (in Russian). DOI: https://doi.org/10.15688/jvolsu4.2018.4.15

УДК 325.1

Дата поступления статьи: 27.10.2017

ББК $66.021+60.723 .5$ Дата принятия статьи: 21.03.2018

\section{УПРАВЛЕНИЕ МИГРАЦИЕЙ В СОВРЕМЕННОЙ РОССИИ: ДОСТИЖЕНИЯ И ПРОСЧЕТЫ ${ }^{1}$}

\section{Алексей Иванович Бардаков}

Волгоградский институт управления (филиал РАНХиГС), г. Волгоград, Российская Федерация

\footnotetext{
Аннотация. Введение. В статье предлагается рассматривать основные проблемы миграции в контексте функционирования властно-управленческой системы России, что несколько изменяет традиционный исследовательский вектор. Такой подход позволяет раскрывать не предикат миграции в качестве предмета исследования, а организационные стороны обустройства мигрантов, что имеет четкую корреляцию с российской властью как объектом исследования.
} 
Memodb. Используемые методы индукции и дедукции позволяют понять частный характер миграции в системе социальных взаимосвязей и выявить причинно-следственную взаимосвязь миграционных процессов со структурами власти. Исследование ведется от общего к частному, то есть изъяны в управленческой деятельности российских властных структур берутся как общее, а затем это проецируется на действия власти по отношению к мигрантам, что позволяет избежать подмены понятий, обрести истинное знание по частному вопросу.

Анализ. Анализ властно-управленческих дефектов в организации миграции в современной России построен на критическом осмыслении социальных миграционных практик и теоретических разработок в этой области знания. Обращается внимание на ограниченность организационного потенциала государственной власти при решении миграционных проблем, обозначаются причины, которые не позволяют местным сообществам участвовать в реализации миграционной политики, раскрывается разнонаправленность социальных и культурных факторов, влияющих на организацию жизни мигрантов, подвергается сомнению необходимость трудовой миграции в России.

Результаты. Выявлены семь изъянов в управлении миграцией, которые сопряжены с неэффективностью государственного управления, отсутствием практики форм непосредственной демократии, с интересами работодателя, который воспринимает мигрантов как дешевую рабочую силу, со слабостью гражданского общества. Устранение выявленных изъянов связывается с совершенствованием всей социальной системы управления посредством расширения форм непосредственной демократии и создания устойчивых механизмов волеизъявления народа по вопросам местного значения.

Ключевые слова: миграция, государственное управление, местное самоуправление, местное сообщество, интеграция.

Цитирование. Бардаков А. И. Управление миграцией в современной России: достижения и просчеты // Вестник Волгоградского государственного университета. Серия 4, История. Регионоведение. Международные отношения. - 2018. - Т. 23, № 4. - С. 176-185. - DOI: https://doi.org/10.15688/jvolsu4.2018.4.15

\section{Введение}

Миграция стала неотъемлемым элементом современных обществ, что предопределяет исследовательский интерес специалистов различных областей знания. Экономисты и юристы, социологи и политологи, психологи, лингвисты и другие специалисты востребованы для построения теоретических концептов и выработки практических рекомендаций по решению существующих проблем миграции в современной России. В рамках реализации гранта «Миграционные риски в полиэтничном регионе: социолого-управленческий анализ» осуществляется политический анализ российских властных структур, взаимодействующих с мигрантами. Исходя из сложившейся мировой социально-политической практики, миграционная политика определяется властью, предлагается раскрыть слабые звенья российской власти, не позволяющие эффективно взаимодействовать с мигрантами. Соответственно цель исследования - выявить изъяны в организационных структурах российской власти, осуществляющих управление миграцией, и внести предложения по совершенствованию миграционной политики.
Существующая структура уровней российской власти определяется сложившейся социально-политической практикой административно-территориального деления России. В зависимости от видов муниципальных образований в России существуют три или четыреуровня власти, то есть две модели организационной структуры власти. Первая модель: государственная власть законодательно закреплена на федеральном и региональном уровнях, а муниципальная власть только на уровне городского округа. Вторая модель: государственная власть реализуется на федеральном и региональном уровнях, а муниципальная власть - в городском округе на уровне: а) города, б) районов (частей) города; в муниципальных районах - на уровне: а) района, б) городских, сельских поселений, образующих район. Соответственно каждый из уровней российской власти задействован в миграционной политике, но их роль и значение в организации жизнедеятельности мигрантов значительно различаются.

\section{Методы исследования}

Гипотетически можно предположить, что основной изъян в управлении миграцией про- 
является в концентрации власти на государственных уровнях, а основная жизнедеятельность мигрантов сосредоточена на муниципальном уровне, а точнее - в местных сообществах (локальных пространствах) муниципальных образований, что значительно затрудняет решение миграционных проблем. Под местным сообществом понимается совокупность социально-культурных взаимосвязей, возникающих между индивидами локальной территории, количество которых позволяет индивиду визуально констатировать свою принадлежность к этому сообществу. Важнейшим организационным признаком местного сообщества является условие, что не только члены этого сообщества знают своего организатора, но и он знает всех.

Надо заметить, что значительная часть исследований по миграции имеет общую структуру и осуществляется по определенной схеме. Миграция (мигранты) выступают объектом, а адаптация, интеграция, правовое обеспечение, трудовая занятость, криминогенная ситуация, связанная с миграцией, и многое другое являются предметом исследования. Признавая правомерность и продуктивность такого подхода, следует заметить, что такая методология исследования важна и значима для теории конструирования, моделирования частного случая и решения конкретной прикладной задачи миграции. Проблемы исследуются с позиции мигрантов или принимающей стороны, а власть как важнейший фактор, субъект миграционных процессов остается в «тени». Конечно, частично это компенсируется тем, что правоведы критически осмысливают действия власти в области законодательного обеспечения миграции, разрабатывая и анализируя правовые акты, но они не подвергают критическому анализу властные структуры.

Видимо, для формирования полноты системы знания о миграции необходимо раскрывать механизмы функционирования власти, определяющей миграционную политику. Такой подход предполагает, что объектом исследования выступает власть, а предметом - изъяны в управлении миграцией, что позволяет рассматривать целостность миграции или совокупность мигрантов как частный случай общего. Такая методология значительно расширяет теоретические возможности научного поиска, так как методом дедукции можно достичь истинного знания о частностях изучаемого предмета, а методом индукции сформировать знания об общем. Соответственно при исследовании феномена «миграция» используется метод индукции, позволяющий раскрыть структурно-функциональную сторону российской власти, которая в нашем случае является общим по отношению к миграции.

Релевантность исследования российской власти в ее миграционном проявлении определяется не только необходимостью мониторинга изменяющегося под влиянием миграционных процессов социума, но и впечатляющей практикой трансформации национального и конфессионального состава современных государств. Надо заметить, что быстрое изменение социально-культурной реальности современных обществ далеко не всегда сопровождается реформированием структур власти, напротив, зачастую органы управления, в том числе и управления миграционными процессами, имеют архаичные формы. Архаичность проявляется в том, что основным субъектом реализации миграционной политики выступают федеральные и региональные органы, а основная жизнедеятельность мигрантов сосредоточена в системе социально-культурных взаимосвязей муниципальных образований.

Между тем, не исключая наличия миграционных неурядиц, не связанных с властью и управлением, уместно заметить, что при современных технологиях воздействия на людей на первый план в миграции выходит управление, структуры власти, занимающиеся миграционной политикой. Раскрывая деятельность структур российской власти и выявляя изъяны в управлении миграцией, можно понять и «озвучить» причины и основания этих недостатков. В этом анализе важно установить объективные и субъективные факторы, детерминирующие изъяны в управлении миграцией, и определить пути их устранения. Видимо, к объективным факторам можно отнести социально-политические и социально-культурные условия, в которых реализуется миграционная политика, а к субъективным - интересы класса крупных собственников и властно-управленческой группы, которые заинтересованы в миграции. 
Такая постановка вопроса будет продуктивна не только для решения теоретических и практических миграционных задач, но и позволит спроецировать познавательную практику на многие другие области социально-политического знания.

\section{Дискуссия}

Анализ властно-управленческих дефектов

$$
\begin{gathered}
\text { в организации миграции } \\
\text { в современной России }
\end{gathered}
$$

При анализе властно-управленческих и миграционных процессов в современной России в отечественной исследовательской литературе уделяется достаточно большое внимание проблемам власти, управления, миграции, но слабо отражается взаимодействие муниципальных органов власти и управления с миграцией, не раскрывается потенциал местных сообществ в этом взаимодействии. Следует отметить, что в научно-практических исследованиях остается открытым вопрос об эффективности воздействия различных уровней российской власти на миграцию в стране.

Так, А.Н. Жеребцов и Е.А. Малышев однозначны в своих утверждениях о том, что в России «...за последние 25 лет, ничего нового для решения проблем организации управления миграцией населения создать не удалось» [2, с. 199]. Характеризуя организационные основы жизнедеятельности мигрантов, авторы выделяют государственное управление миграцией как основное и единственно возможное средство, инструментарий миграционной политики, определяя его как деятельность «...по реализации государственной политики в сфере миграции населения в Российской Федерации» [2, с. 201]. Признавая продуктивность таких выводов для практики и теории миграции, уместно заметить, что государственное управление не обладает тотальностью контроля за жизнедеятельностью не только мигрантов, но и индивидов принимающей стороны, так как в России, кроме государственного управления, конституционно закреплено местное самоуправление. И значим здесь не факт законодательного закрепления, а практика взаимосвязей между индивидами, малыми социально-культурными группами, которая не может быть организована и проконтролирована государством. Миграция, как и другие социальные феномены, является частью социальной системы, где государственное управление остается необходимостью и ему свойственна созидательность, но миграция - это и биотические, и культурные взаимосвязи, которые находятся вне пределов компетенции не только формальных, но и реальных организационных основ отдельных индивидов, местных сообществ.

Диалектическую мысль о развитии конкретного региона «пришлым» населением высказывают Т.С. Лыткина и В.В. Фаузер. Авторы полагают, что преобладание мигрантов на определенной территории может быть выгодно власти, но оно не позволяет коренному населению «...сформулировать свой собственный интерес в развитии территории» [5, c. 107]. Отмечая большой вклад мигрантов в развитие всей социальной системы региона, исследователи обращают внимание на утрату уникальной культуры, разрушение традиций, отсутствие возможности у местного населения распоряжаться своими природными ресурсами [5, с. 107]. Надо заметить, что речь идет о Республике Коми, то есть рассматривается управление и регулирование миграционными процессами на уровне региона. Безусловно, на данном уровне решаются значимые государственные задачи в области экономики, политики, обороноспособности и многое другое, но авторы ведут речь об утраченной культуре, традициях и функции распоряжения собственностью. Достаточно сложно согласиться с авторами в том, что эти социальнокультурные составляющие соотносимы с уровнем региона. Видимо, культура и традиции имеют корреляцию, прежде всего, с местными сообществами, да и процесс распоряжения природными ресурсами возможен только через волеизъявление населения местного сообщества, поскольку конкретное местное сообщество воспринимает (исторически владеет) определенную территорию как неотъемлемую часть своего бытия. Распоряжение же на уровне региона не может осуществляться без непосредственного участия институтов государства или их участия в регулировании этих процессов. 


\section{ПОЛИТИЧЕСКИЕ НАУКИ И РЕГИОНОВЕДЕНИЕ}

Надо заметить, что российская социально-политическая система не имеет практики участия местных сообществ в распоряжении предметом общественной собственности. В отечественной истории так сложилось, что государство остается основным распорядителем природных ресурсов, несмотря на то что в политических декларациях основным владельцем и распорядителем обозначен многонациональный российский народ. Конечно, декларации о распоряжении собственностью народом посредством его участия в избрании органов власти на федеральном и региональном уровне, а также в большинстве городских округов и муниципальных районов имеют рациональный смысл, так как в условиях доминанты вопросов государственного значения организация жизнедеятельности общества возможна лишь в системе властно-управленческих отношений.

Совершенно иная ситуация складывается с функцией распоряжения природными ресурсами как предметом собственности в местных сообществах, которые имманентно присущи не только городским и сельским поселениям, но и городским округам. Члены местных сообществ в своей повседневности соприкасаются и нередко пользуются природными ресурсами, но практически никогда не распоряжаются ими, что порождает инфантилизм и иждивенчество. Власть не допускает возникновение организационных основ местных сообществ, так как такое обустройство предполагает ограничение распорядительной функции органов власти всех уровней. Отсутствие организационных основ местных сообществ отражается и на миграционной сфере. Члены местных сообществ, не имеющие «голоса» при распоряжении собственностью, не могут быть активными радетелями сложившегося образа жизни, традиций, поскольку за них решение принимает власть.

Управленческий аспект в исследованиях по миграции встречается нередко, но его основная слабость состоит в том, что предмет исследования раскрывается в парадигмах государственного управления, однако жизнь мигрантов далеко не всегда сопряжена с вопросами государственного значения. Соответственно в подобных работах не отражается важнейшая часть жизнедеятельности мигран- тов в местных сообществах. Можно согласиться с О.Н. Шерстобоевым в том, что упрощение государством процедур легализации мигрантов способствует улучшению качественного состава прибывающих в Россию, а эффективная реформа государственных административных органов позволит обеспечить оптимальное соотношение регулятивной и охранительной функций государства в миграционной политике [9, с. 151]. В этом правильном утверждении хотелось бы обратить внимание на некоторые аспекты.

Во-первых, признавая значимость правовых механизмов для легализации мигрантов, следует отметить, что законодательная база по легализации мигрантов, как правило, действительна на всей территории государства, но мигранты остаются жить далеко не во всех социокультурных пространствах. Такое обстоятельство свидетельствует о том, что государству, органам власти не подвластны все территории и сферы жизнедеятельности людей при осуществлении миграционной политики, то есть далеко не всегда местные сообщества разрешают жить мигрантам на своей территории.

Во-вторых, административная реформа всегда коррелируется с политическими целями и задачами, что предполагает совершенствование управления, то есть внедрение новых механизмов навязывания воли. Возникновение новых механизмов управления имеет объективный характер, поскольку социальная система подвержена постоянному изменению. Соответственно регулятивная и охранительная функции государства в миграционной сфере являются частным случаем в совершенствовании государственного управления, но они не могут распространяться на жизнь местных сообществ, где сконцентрирована значительная часть жизни мигрантов.

Особый интерес для раскрытия изъянов в управлении миграцией представляет подход, предлагаемый Т.Н. Юдиной, которая обращает внимание на тенденцию культурного и социального размежевания мигрантов по этническому основанию и делает вывод, что если этническое разнообразие не трансформировать в «социальный капитал», то это приведет к конфликтам. Исследователь также сетует на то, что городская политика строится 
на необходимости избегать подобных конфликтов любой ценой [10, с. 89]. Из контекста высказанного суждения видно, что автор не различает консервацию конфликта и упреждение конфликта, полагая, что конфликт должен пройти этапы своего становления и разрешиться при достижении пика своего развития. Этот «романтизм» вполне уместен в теоретическом конструировании конфликтов, но практика социальных конфликтов, имеющих этническую форму, в подавляющем большинстве случаев трагична, поэтому задача научного знания не допустить, или, по крайней мере, предупредить общество о возможности трагедии. По этому поводу весьма взвешенной и перспективной выглядит позиция М.Н. Козюка, предлагающего технологию медиации, суть которой сводится к примирению конфликтующих сторон $[4$, с. 21$]$. Позитив этой технологии в том, что конфликтующие стороны объективно заинтересованы в мире и добрососедстве, поскольку они жили и будут жить в одном социально-культурном пространстве, местном сообществе.

Особое возражение вызывает выделение Т.Н. Юдиной культурной и социальной составляющих как основания размежевания миграционных этнических групп между собой, а также по отношению к принимающей группе лиц, поскольку это предложение строится на ложных методологических посылках. Социальное и культурное имеют четкую корреляцию соответственно с социумом и культурой, качественная определенность которых совершенно различна. Если социум представляет собой совокупность, целостность общественных отношений, то культура - целостность добродетельных, гуманистических отношений. И как бы это не звучало банально, социум формирует социальные свойства, социальность индивида, а культура «возделывает» его человеческие свойства. Социальность, имеющая свои истоки в трудовой деятельности, с необходимостью производит и сохраняет неравенство, несправедливость и многие другие антигуманные явления, поэтому разделение, размежевание миграционных групп на поле социальности вполне закономерно, так как они являются неотъемлемыми элементами социальной системы. Более того, поиск или разработка теоретических концепций, позво- ляющих снять конфликт между социальными группами (этническими, религиозными, экономическими, политическими и др.) в рамках социальности, является делом бесперспективным. Грамотная, профессиональная деятельность руководителей, политических акторов, органов власти может снять напряженность в конфликтной ситуации, помочь найти компромисс конфликтующим сторонам, определить перспективы оптимизации взаимодействия между социальными группами, но устранить конфликт единожды, раз и навсегда невозможно.

Преодоление размежевания, снятие конфликтности может быть только в формах бытия культуры, то есть культурной составляющей, которая по своей сути не может быть основанием противостояния, конфликта. Надо заметить, что при исследовании миграции как термин, так и понятие «культура» используется достаточно часто. Так, в коллективном издании отмечается, что молодежь часто и откровенно враждебно относится «...к представителям иных культур» [6, с. 126]. Авторы вольно или невольно проводят мысль о том, что культура может быть основанием противостояния, конфликта между социальными группами, индивидами, с чем согласиться достаточно сложно.

Культура объединяет, культурный человек объективно заинтересован в наличии иной культуры, так как она способствует развитию его гуманистических свойств. Данное обстоятельство является важнейшим фактором в управлении миграцией, и самое интересное, что управленцы, политические руководители в своем большинстве это все понимают. Однако объединение не становится доминирующей тенденцией, интеграция мигрантов между собой и жителями принимающей стороны при действующей властно-управленческой системе не может осуществиться. Такая ситуация не является случайностью или заблуждением, она детерминирована финансово-экономическими запросами собственников, которые заинтересованы в дешевой рабочей силе, и должностных лиц власти, отчуждающих труд, конечно, не только мигрантов, но и местных жителей.

Надо заметить, что отчуждение труда у мигрантов имеет и своеобразное «теоретичес- 
кое» обоснование. Игнорирование биотической и культурной составляющих в миграционных процессах приводит к абсолютизации социального вида миграции. Так, Д.В. Житин ведет речь о двух методах управления миграционными процессами, полагая, что методы экономического стимулирования востребованы современной российской демократией, а командно-административные методы свойственны только прошлым отечественным общественным порядкам [3, с. 128]. Такая позиция вызывает возражение уже только потому, что «не хлебом единым жив человек». Индивид, социальная группа могут перемещаться ведь не только для того, чтобы улучшить свое социальное (экономическое) положение, но и для сохранения жизни при техногенных катаклизмах, социальных катастрофах, а также менять место жительства для индивидуального саморазвития, самореализации. Важным обстоятельством в понимании экономических методов управления миграцией является вывод об отсутствии экономических предпосылок для миграции, сделанный B.M. Молокановым, который подтверждает это убедительной аргументацией [7, с. 34-36]. На этом основании можно делать вывод о том, что мигранты нужны собственнику в качестве дешевой рабочей силы, а властно-управленческим органам в качестве причины укрепления своей распорядительной функции. На федеральном и региональном уровнях власти сконцентрированы основные компетенции по работе с миграцией, муниципальным органам отведена вспомогательная функция работы с мигрантами, а уровень реального самоуправления, то есть местные сообщества практически исключены из этого процесса, что и является основной проблемой управления миграцией.

В научно-исследовательской литературе затрагивается вопрос участия населения в решении миграционных проблем посредством общественных институтов и форм самоуправления, но он требует своей дальнейшей проработки. Важное место в классификации составляющих миграционной политики отводит общественным институтам и местному сообществу И.В. Василевская [1, с. 105]. Соглашаясь с автором в том, что они выполняют значимую функцию в миграционной политике, следует обратить внимание на общественные институты, которые в своем большинстве по сложившейся российской традиции являются вспомогательными механизмами реализации государственной политики практически во всех сферах жизни российского общества. А местное сообщество не обладает полномочиями по осуществлению самостоятельной деятельности не только в миграционной сфере, но и даже в вопросах местного значения, которые в политических и правовых декларациях обозначены как дело самих жителей.

Наиболее точна в характеристике взаимоотношений мигрантов и принимающего местного сообщества И.С. Тарбастаева. Автор обращает внимание на факт их проживания на одной территории, но при этом ментально и культурно они не соприкасаются [8, с. 166]. Устранение сложившейся практики автору видится в активизации ТОС (территориальное общественное самоуправление), которое наделено правом гармонизации межэтнических отношений и может реально помогать местной власти $[8$, с. 168]. Далее констатируется, что «...потенциал ТОС по интеграции мигрантов в местное социокультурное пространство напрямую зависит от готовности граждан жить и взаимодействовать с представителями другой этнической культуры» [8, с. 171]. Разделяя главный вывод И.С. Тарбастаевой о том, что без местной власти, без местного сообщества миграционные проблемы не решаемы, следует заметить, что, говоря о «...готовности граждан...», необходимо обратить внимание на следующие обстоятельства. Во-первых, в России нет механизмов реализации воли местного сообщества по вопросам местного значения, а обозначенные в законе № 131-Ф3 от 06.10.2003 формы непосредственной демократии не имеют широкой практики реализации, а некоторые из них, например, публичные слушанья, являются ничем иным как имитацией демократии. Отсутствие практики участия у граждан в принятии решений по вопросам местного значения не позволяет гражданам быть готовым к самостоятельной деятельности не только в сфере миграции, но и в других вопросах местного сообщества. Во-вторых, необходимо четко разделять волеизъявление как участие членов местного сообщества в организации своей жизни и организационную (исполнительно-распоря- 
дительную) функцию жизнедеятельности местного сообщества, которую может выполнять только организатор профессионал (управленец). Управление-это сложный социальный процесс, требующий особых навыков, больших знаний, а самоуправление на порядок выше управления, поэтому требует профессионала организатора. Всякие утверждения о том, что народ сам организует свою жизнь, связаны с незнанием предмета или же лукавством. В местных сообществах люди должны иметь возможность изьявить свою волю, а организатор самоуправления, органы власти должны ее реализовать, тогда и коммуникация между принимающей стороной и мигрантами обретет совершенно иные очертания.

\section{Результаты}

Исследуя управление миграцией, удалось выявить ряд изъянов в этом процессе.

Первый: государственное управление, являясь необходимостью организационного процесса миграции, тем не менее, не может эффективно организовывать биотические и культурные взаимосвязи мигрантов, поскольку они находятся вне пределов компетенции государственных структур.

Второй: все попытки структур власти распространить регулятивную и охранительную функции государства на мигрантов не достигают цели, так как значительная часть социально-культурных взаимосвязей мигрантов сосредоточена в местных сообществах, где объективно востребовано местное самоуправление.

Третий: существующая система социального управления в современной России не позволяет местным сообществам участвовать в распоряжении собственностью, что предопределяет их инфантильность не только к вопросам местного значения, но и миграционным процессам.

Четвертый: интеграция мигрантов не обретает устойчивый характер, так как собственник (работодатель) заинтересован в дешевой рабочей силе, а структуры власти в укреплении субъектно-объектных взаимосвязей по отношению к мигрантам, что предполагает изоляцию миграционных групп.

Пятый: организационные компетенции по работе с мигрантами сосредоточены на фе- деральном и региональном уровнях, а те вспомогательные функции, которыми наделены органы муниципального управления, трудно реализуемы, поскольку властно-управленческие структуры не допускают волеизъявления местных сообществ.

Шестой: отсутствие широкой практики самоуправления предопределяет сохранение субъектно-объектных отношений между структурами государственной власти и институтами гражданского общества при реализации миграционной политики, что затрудняет интеграционные процессы.

Седьмой: отсутствие организационных основ жизнедеятельности местных сообществ в целом и руководителей, работающих на постоянной, возмездной основе, этих социальнокультурных образований в частности, не позволяет решать эффективно значительную часть проблем миграции.

Выход из этой ситуации видится в оптимизации соотношения государственного управления и местного самоуправления в осуществлении миграционной политики. Успех управления миграцией в значительной степени сопряжен с развитием самоуправления в России, поскольку формы непосредственной демократии имеют прямое отношение к развитию человека. Индивид обретает и развивает свои гуманистические свойства, прежде всего, в местном сообществе, где роль социальной иерархии минимизирована, а культурные факторы становятся доминирующими, что способствует интеграции, идентификации индивидов по признакам территории проживания.

\section{ПРИМЕЧАНИЕ}

${ }^{1}$ Статья подготовлена при поддержке гранта РГНФ № 16-13-34011 «Миграционные риски в полиэтничном регионе: социолого-управленческий анализ».

\section{СПИСОК ЛИТЕРАТУРЫ}

1. Василевская, И. В. Миграционная политика в системе современного государственного управления / И. В. Василевская // Вестник РГГУ. Серия: Экономика. Управление. Право. - 2014. № 3 (125). - С. 102-109. 
2. Жеребцов, А. Н. Современные организационные и административно-правовые проблемы государственного управления миграцией населения / А. Н. Жеребцов, Е. А. Малышев // Общество и право. - 2017. - № 2 (60). - С. 198-204.

3. Житин, Д. В. Методологические основы управления миграционными процессами / Д. В. Житин // Вестник Санкт-Петербургского университета. Серия 7, Геология. География. -2009 . - № 1. C. $117-128$.

4. Козюк, М. Н. Медиативные технологии в деятельности должностных лиц местного самоуправления по противодействию этническим конфликтам в местных сообществах / М. Н. Козюк // Научный вестник Волгоградского филиала РАНХиГС. Серия: Политология и социология. - 2017. - № 1. C. $17-22$.

5. Лыткина, Т. С. Государственное управление принудительной миграцией как способ освоения Севера России в 1930-1950-е гг. / Т. С. Лыткина, В. В. Фаузер // Журнал социологии и социальной антропологии. -2016. - Т. XIX, № 1 (84). - С. 90-109.

6. Миграционные процессы современной России: политическое прогнозирование в управлении : учеб.-метод. пособие / Е. Л. Рябова, Т. М. Бормотова, А. Ф. Радченко, Т. Р. Суздалева. - М. : Междунар. издат. центр «Этносоциум», 2015. - 154 с.

7. Молоканов, В. М. Концепция нехватки рабочих рук в экономике России с позиции современной экономической теории / В. М. Молоканов // Научный вестник Волгоградского филиала РАНХиГС. Серия: Политология и социология. 2016. - № 4. - С. 34-36.

8. Тарбастаева, И. С. Роль территориального общественного самоуправления в межэтнической интеграции мигрантов / И. С. Тарбастаева // Сибирский философский журнал. - 2017. - Т. 15, № 2. С. 164-174.

9. Шерстобоев, О. Н. Государственное управление в сфере миграции: административно-правовой аспект / О.Н.Шерстобоев // Вестник Сибирского университета потребительской кооперации. 2016. - № 1 (16). - С. 151-156.

10. Юдина, Т. Н. Миграция и этническое разнообразие в московском мегаполисе: основные подходы к управлению / Т. Н. Юдина // Материалы Афанасьевских чтений. - 2015. - Т. 1, № 13. - С. 87-94.

\section{REFERENCES}

1. Vasilevskaya I.V. Migratsionnaya politika v sisteme sovremennogo gosudarstvennogo upravleniya [Migration Policy in the Modern State Management System]. Vestnik RGGU. Seriya: Ekonomika. Upravlenie. Pravo, 2014, no. 3 (125), pp. 102-109.
2. Zherebtsov A.N., Malyshev E.A. Sovremennye organizatsionnye i administrativno-pravovye problemy gosudarstvennogo upravleniya migratsiey naseleniya [Modern Organizational and Administrative Legal Problems of State Management of Population Migration]. Obshchestvo i pravo [Society and Law], 2017, no. 2 (60), pp. 198-204.

3. Zhitin D.V. Metodologicheskie osnovy upravleniya migratsionnymi protsessami [Methodological Bases of Migratory Processes Management]. Vestnik Sankt-Peterburgskogo universiteta. Seriya 7, Geologiya. Geografiya, 2009, no. 1, pp. 117-128.

4. Kozyuk M.N. Mediativnye tekhnologii v deyatelnosti dolzhnostnykh lits mestnogo samoupravleniya po protivodeystviyu etnicheskim konfliktam v mestnykh soobshchestvakh [Mediative Technologies in the Activity of Local Government Officials on Counteracting Ethnic Conflicts in Local Communities]. Nauchnyy vestnik Volgogradskogo filiala RANKhiGS. Seriya: Politologiya i sotsiologiya, 2017, no. 1, pp. 17-22.

5. Lytkina T.S., Fauzer V.V. Gosudarstvennoe upravlenie prinuditelnoy migratsiey kak sposob osvoeniya Severa Rossii v 1930-1950-e gg. [State management of forced migration as a way of mastering the North of Russia in the 1930s-1950s]. Zhurnal sotsiologii $i$ sotsialnoy antropologii [Journal of Sociology and Social Anthropology], 2016, vol. XIX, no. 1 (84), pp. 90-109.

6. Ryabova E.L., Bormotova T.M., Radchenko A.F., Suzdaleva T.R. Migratsionnye protsessy sovremennoy Rossii: politicheskoe prognozirovanie v upravlenii [Migration Processes of Modern Russia: Political Forecasting in Management]. Moscow, Etnosotsium Publ., 2015. 154 p.

7. Molokanov V.M. Kontseptsiya nekhvatki rabochikh ruk v ekonomike Rossii s pozitsii sovremennoy ekonomicheskoy teorii [The Conception of a Shortage of Workers in the Russian Economy from the Perspective of Modern Economic Theory]. Nauchnyy vestnik Volgogradskogo filiala RANKhiGS. Seriya: Politologiya i sotsiologiya, 2016, no. 4, pp. 34-36.

8. Tarbastaeva I.S. Rol territorialnogo obshchestvennogo samoupravleniya v mezhetnicheskoy integratsii migrantov [The Role of Territorial Public Self-Government in Inter-Ethnic Integration of Migrants]. Sibirskiy filosofskiy zhurnal, 2017, vol. 15, no. 2, pp. 164-174.

9. Sherstoboev O.N. Gosudarstvennoe upravlenie v sfere migratsii: administrativno-pravovoy aspekt [State Administration in the Sphere of Migration: Administrative and Legal Aspect]. Vestnik Sibirskogo universiteta potrebitelskoy kooperatsii, 2016, no. 1 (16), pp. 151-156. 
А.И. Бардаков. Управление миграцией в современной России: достижения и просчеты

10. Yudina T.N. Migratsiya i etnicheskoe raznoobrazie v moskovskom megapolise: osnovnye podkhody k upravleniyu [State Administration in the
Sphere of Migration: Administrative and Legal Aspect]. Materialy Afanasyevskikh chteniy, 2015, vol. 1, no. 13, pp. 87-94.

\section{Information about the Author}

Aleksey I. Bardakov, Doctor of Sciences (Politics), Professor, Department of Public Administration and Political Science, Volgograd Institute of Management - Branch of Russian Presidential Academy of National Economy and Public Administration, Gagarina St., 8, 400131 Volgograd, Russian Federation, bardakov@mail.ru,https://orcid.org/0000-0003-1349-4997

\section{Информация об авторе}

Алексей Иванович Бардаков, доктор политических наук, профессор кафедры государственного управления и политологии, Волгоградский институт управления - филиал РАНХиГС, ул. Гагарина, 8, 400131 г. Волгоград, Российская Федерация, bardakov@mail.ru, https://orcid.org/ 0000-0003-1349-4997 